\title{
Growing concern over medical students' excessive drinking
}

Cite as: CMAJ 2018 October 9;190:E1215. doi: 10.1503/cmaj.109-5662

Posted on cmajnews.com on Sept. 19, 2018.

M edical school is stressful and many medical students use alcohol to blow off steam, sometimes in weekend binges. It's a pattern to which schools and student groups are paying more attention, considering high rates of burnout and suicide in the profession.

"There is a tendency in medicine to work hard and then on weekends, people go a little bit overboard," said Victor Do, who leads the wellness portfolio at the Canadian Federation of Medical Students (CFMS). "We're not immune to using alcohol to cope with stress."

The CFMS has replaced its one-month wellness program with a long-term campaign to offer more comprehensive support to students dealing with stress. According to Do, medical students may not use alcohol at higher rates than other Canadians their age, but their pattern of letting loose on weekends may put them at higher risk for binge drinking. A 2009 University of Calgary survey, one of the only studies of alcohol use among Canadian medical students, found that although medical students consumed less alcohol than their peers, a higher proportion were at risk for problem drinking.

A similar pattern is seen around the world. A survey of medical students in the United Kingdom found that one in 10 exceeded weekly alcohol consumption guidelines. Meanwhile, a national study of American medical students found that one in three met the diagnostic criteria for alcohol abuse, double the rate of other students.

In the American study, alcohol abuse was strongly associated with burnout, depression, lower quality of life and higher student debt, said lead author Dr. Liselotte Dyrbye of the Mayo Clinic in Rochester, Minnesota. The links with burnout and depression were not surprising and had been found in other studies, she said. But the researchers were not expecting the link to student debt. "No one had looked at debt before," Dyrbye explained.

That link is particularly worrying, she said, because the average medical student debt is rising in the United States - from $\$ 125000$ in 2000 to $\$ 190000$ in 2016, according to the Association of American Medical Colleges. The average debt for Canadian medical students is around $\$ 160000$. It's certainly a source of stress, said Do, but there are no Canadian data linking that debt to alcohol use.

Dyrbye's study also found that $9 \%$ of medical students had thoughts of suicide - a "stunningly high" proportion. "We need to advocate for approaches that support more positive coping strategies," including strategies to reduce burnout and the cost of medical education, she said.

Many medical schools are now taking a greater interest in students' wellbeing, said Lisa Merlo, a clinical psychologist at the University of Florida in Gainsville. She led a study that found $70 \%$ of medical students at the university admitted to binge drinking. "The University of Florida now has a mandatory longitudinal wellness program, which didn't exist when we did the survey five years ago," she said.

The CFMS intends to provide similar ongoing support through its new National Wellness Program. Previously, the CFMS spent one month each year promoting wellness. The new program, launched in April, runs for 10 months, with two-month blocks focused on different themes: nutrition, mental health, physical wellness and relationships. Discussions about problematic drinking could fit within any of the five themes, said Do. "If alcohol is an issue, the best way to address it is not just with sessions about alcohol."

Brian Owens, St. Stephen, NB

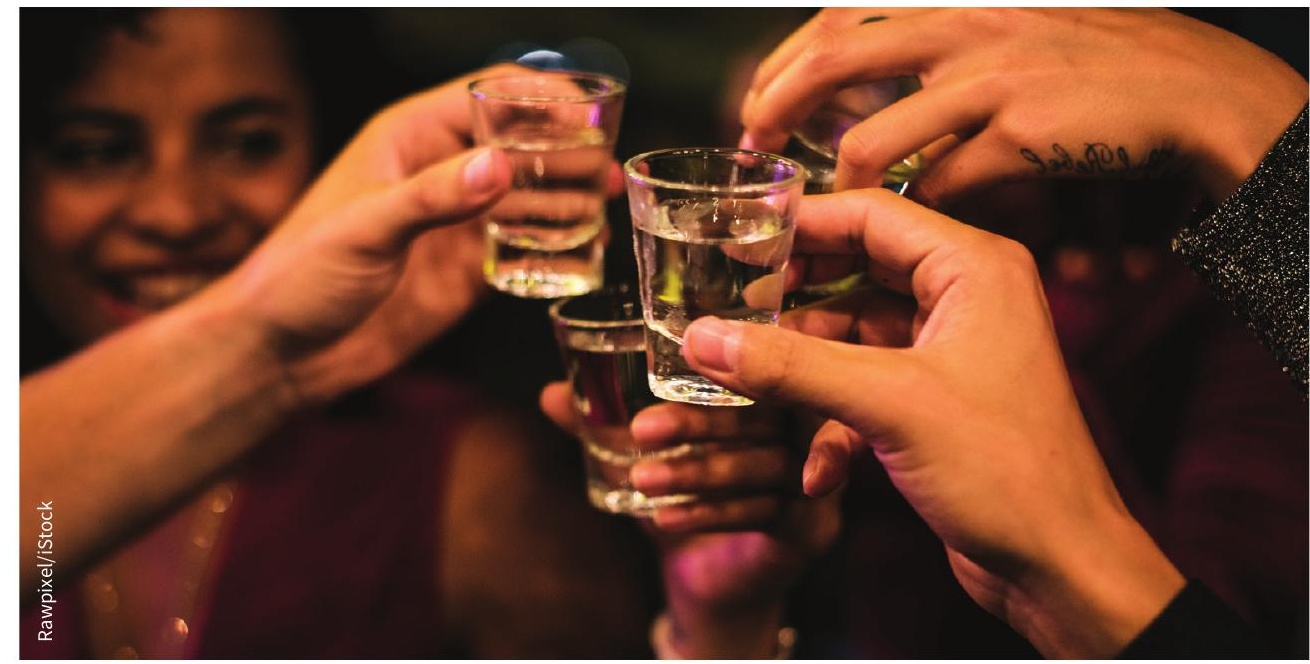

Medical schools and student groups are stepping up wellness supports to tackle stressors linked to alcohol abuse. 